\title{
Salt and drought stress affects electron transport chain genes in rice
}

\author{
Deepali Varshikar ${ }^{1, *}$, Fui Ching Tan ${ }^{2}$ \\ ${ }_{1}^{1}$ Biosciences Department, Malaysia University of Science and Technology, 47301 Petaling Jaya, Selangor, Malaysia \\ ${ }^{2}$ School of Foundation Studies, Xiamen University Malaysia Campus, Bandar Serenia, 43900 Sepang, Selangor, Malaysia
}

\section{ARTICLE INFO}

\section{Article history:}

Received 5 July 2016

Received in revised form

21 October 2016

Accepted 10 November 2016

\section{Keywords:}

Salt and drought stress

Apocytochrome $f$

DDRT-PCR

\begin{abstract}
A B S T R A C T
Rice is well known as a salt and drought sensitive crop. Salt and drought stresses greatly affect the growth and productivity of rice plants. To study the molecular response of rice to these abiotic stresses, 14 day-old whole seedlings of the MR253 rice variety were subjected to varying duration of drought- and salt-stress treatments. Using the Differential Display Reverse Transcription Polymerase Chain Reaction (DDRT-PCR), two putative genes were identified; one encodes the apocytochrome $f$ precursor while the other codes for the ATP synthase B chain. The expression of the apocytochrome $f$ precursor was downregulated by 10 -fold compared to that of the untreated seedlings after one day of drought-stress treatment but its expression seemed to recover back up to levels similar to those of the untreated seedlings if the duration of drought stress was extended for more than one day. On the other hand, the ATP synthase B chain showed a two-fold increase in expression relative to that of the untreated seedlings after one hour of saltstress treatment but the level of its expression dropped back to those similar to the untreated seedlings if the duration of salt stress went beyond one hour. These findings suggest that genes encoding the apocytochrome $f$ precursor and the ATP synthase B chain seem to play a role in the early molecular response of rice plants to abiotic stresses.
\end{abstract}

(C) 2017 The Authors. Published by IASE. This is an open access article under the CC BY-NC-ND license (http://creativecommons.org/licenses/by-nc-nd/4.0/).

\section{Introduction}

Rice is the staple food for more than half of the global human population. The demand for rice is increasing with the exponential rise in human population; to keep up with the boom in human population, agricultural production needs to increase by $70 \%$ to meet the daily requirement of food worldwide by 2050 (FAO, 2009). The challenge of meeting the demand for food is complicated by the fact that environmental vagaries are taking a toll on rice production since rice plants are sensitive to various abiotic stresses (Shanker and Venkateswarlu, 2011). Salinity and drought are two major sources of abiotic stress affecting rice plants.

A similar mechanism of stress response seems to be at work when plants are under salt and drought stresses (Rodríguez et al., 2006). High salinity and drought stresses are known to cause dehydration, and consequently, trigger the biosynthesis of the phytohormone abscisic acid whose activity in turn

\footnotetext{
* Corresponding Author

Email Address: deepalivarshikar@yahoo.com (D. Varshikar) https://doi.org/10.21833/ijaas.2017.02.018

2313-626X/C 2017 The Authors. Published by IASE.

This is an open access article under the CC BY-NC-ND license

(http://creativecommons.org/licenses/by-nc-nd/4.0/)
}

induces the expression of genes that regulate biochemical and physiological processes essential for plants to adapt to saline or drought conditions (Boudsocq and Laurière, 2005; Fujita et al., 2011; Finkelstein et al., 2002; Yamaguchi-Shinozaki and Shinozaki, 2006). This study aims to uncover some of the rice genes whose expression changes in response to short-term salt and drought stresses.

\section{Materials and methods}

\subsection{Plant material}

The seeds of the MR 253 rice variety were obtained from MARDI (Malaysian Agricultural Research and Development Institute, Serdang, Malaysia) and stored at $4^{\circ} \mathrm{C}$ until being used.

\subsection{Growth and maintenance of rice seedlings}

Rice seeds were soaked overnight in water and then were sown on a mixture of organic compost and black soil (3:7) in pots. Twenty seeds were placed in each pot and about $35-40 \%$ of them germinated. Among the few germinated seedlings, only one healthy seedling per pot was chosen to continue its growth and development while the rest were 
removed. The seedlings in pots were arranged according to the randomized complete block design (RCBD) and maintained under a cycle of 16 hours light and 8 hours dark at $25^{\circ} \mathrm{C}$ (Hakim et al., 2010; Lee et al., 2011). Fourteen days after sowing, seedlings were subjected to either drought stress treatments for duration of 1 day, 2 days or 4 days, or salt stress treatments that lasted $15 \mathrm{~min}, 1$ hour, 3 hours or 6 hours. Each of the treatments was carried out in duplicates. After the completion of the treatments, whole seedlings were harvested and their total RNA was extracted.

\subsection{RNA extraction and cDNA synthesis}

Total RNA extraction was performed using the RandA Blue Total RNA Extraction Kit (iNtRON biotechnology Inc., Korea) according to the manufacturer's instructions. Using the isolated total RNA as a template, the first strand cDNA was synthesized using the Tetro cDNA Synthesis Kit (Bioline Inc, UK) according to the manufacturer's instructions. The newly synthesized cDNA was stored at $-20^{\circ} \mathrm{C}$ until being used.

\subsection{Differential display reverse transcription polymerase chain reaction (DDRT - PCR)}

A total of 20 random forward primers were used in the DDRT-PCR analysis (Liang and Pardee, 1992; Varshikar and Ching, 2015). All the primers were custom-made by Bioneer Inc (Korea). Using the first strand cDNA as a template, a random forward primer was paired with a reverse primer in the form of an oligo $\mathrm{d}(\mathrm{T})_{18}$ in a total reaction volume of $50 \mu \mathrm{l}$ which contained $0.8 \mu \mathrm{l}$ first strand cDNA, $0.5 \mu \mathrm{l}$ random primer, $0.5 \mu \mathrm{l}$ oligo $\mathrm{d}(\mathrm{T})_{18}$ primer, $23.2 \mu \mathrm{l}$ $\mathrm{H}_{2} \mathrm{O}$ and $25 \mu \mathrm{l}$ Taq master mix (MyTaq Mix PCR Kit, Bioline Inc, UK). The rice ACTIN 1 gene was used as a positive control for the reaction and the target sequence was amplified using two specific primers (Act1-F: 5'-CATGCTATCCCTCGTCTCGACCT-3' and
Act1-R: 5'- CGCACTTCATGATGGAGTTGTAT-3') (Xu et al., 2002). All the amplification reactions were carried out under the following conditions: 35 cycles of $95^{\circ} \mathrm{C}$ for $5 \mathrm{~min}, 40^{\circ} \mathrm{C}$ for $30 \mathrm{sec}$ and $72^{\circ} \mathrm{C}$ for $1 \mathrm{~min}$ using a PCR thermo-cycler (MJ Research Incorporated, USA).

\subsection{Agarose gel electrophoresis and purification of amplified products}

The PCR-amplified products were analyzed by agarose gel electrophoresis on a $1.5 \% \mathrm{w} / \mathrm{v}$ agarose with $1 \mathrm{x}$ TAE buffer. The gel was stained with the Red $\mathrm{Safe}^{\mathrm{TM}}$ nucleic acid staining dye and visualized under UV illumination. All images were captured using a compact canon camera with a resolution of 12.1 megapixels. Discrete DNA fragments were purified using a gel purification kit (Bioneer Inc, Korea) according to the manufacturer's instructions.

\subsection{Sequencing and data analysis}

Purified DNA fragments were sequenced using an automated DNA sequencer ABI3730xl DNA analyzer (Bioneer Inc, Korea). The sequence information was analyzed using the online tools provided by the National Center for Biotechnology Information (NCBI, USA) and the MSU Rice Genome Annotation Project (http://rice.plantbiology.msu.edu/index. shtml). The sequences were further searched in KEGG pathway server for metabolic pathway analysis (http://www.genome.ad.jp/kegg).

\subsection{Real time quantitative PCR}

All primers used for the real-time quantitative PCR were designed using the Primer-BLAST tool hosted by NCBI. The size of the primers ranged from 20 to 22 nucleotides with a melting temperature $\left(\mathrm{T}_{\mathrm{m}}\right)$ of $60^{\circ} \mathrm{C}$, and a GC content of $40-60 \%$ (Table 1 ).

Table 1: Sequences of primers for real-time quantitative PCR and their corresponding Amplicon lengths and amplification

\begin{tabular}{|c|c|c|c|c|}
\hline $\begin{array}{c}\text { Encoded Protein of } \\
\text { Target or Reference } \\
\text { Gene }\end{array}$ & Primer Sequence $\left(5^{\prime}-3^{\prime}\right)$ & $\begin{array}{l}\text { Source of cDNA } \\
\text { Template }\end{array}$ & $\begin{array}{l}\text { Amplicon } \\
\text { Length (bp) }\end{array}$ & $\begin{array}{l}\text { Amplification } \\
\text { Efficiency }\end{array}$ \\
\hline \multirow{2}{*}{$\begin{array}{l}\text { Apocytochrome } f \\
\text { precursor }\end{array}$} & $\begin{array}{l}\text { F1: TTCGTCCAGTTGCTTCTCGT } \\
\text { R1: TGGGTAAAGGAACAGATGAC }\end{array}$ & $\begin{array}{l}\text { Drought-stress } \\
\text { treated and } \\
\text { untreated }\end{array}$ & 136 & 2.00 \\
\hline & $\begin{array}{l}\text { F2: TCGTCCAGTTGCTTCTCGTG } \\
\text { R2: GGGATCTGTGATTGGACATG }\end{array}$ & $\begin{array}{l}\text { Salt-stress } \\
\text { treated and } \\
\text { untreated }\end{array}$ & 176 & 2.00 \\
\hline $\begin{array}{l}\text { ATP synthase B } \\
\text { chain }\end{array}$ & $\begin{array}{l}\text { F3: GGGGGTACTCTTTCTACAAC } \\
\text { R3: TACTAGAAGGGGCACCCTGC }\end{array}$ & $\begin{array}{l}\text { Salt-stress } \\
\text { treated and } \\
\text { untreated }\end{array}$ & 140 & 1.78 \\
\hline Ubiquitin & $\begin{array}{l}\text { Ubq-F: CCGTTTGTAGAGCCATAATTGCA } \\
\text { Ubq-R: AGGTTGCCTGAGTCACAGTTAAGTG }\end{array}$ & $\begin{array}{l}\text { Salt- and } \\
\text { drought-stress } \\
\text { treated and } \\
\text { untreated }\end{array}$ & 76 & 1.85 \\
\hline
\end{tabular}

The expression level of each target gene transcript in salt- and drought-stress treated and untreated seedlings was quantified by the Roche LightCycler® 2.0 using the reaction mix
LightCycler® FastStart DNA Master ${ }^{\text {PLUS }}$ SYBR Green I (Roche, USA). Each of the amplification reactions was performed triplicate in a volume of $20 \mu \mathrm{l}$, which contained $2 \mu \mathrm{l}$ TaqMan Master Mix SYBR Green, $1 \mu \mathrm{l}$ 
each of the $5 \mathrm{mM}$ forward and reverse primers and $1.5 \mu$ first strand cDNA. The amplification conditions were as follows: 1 cycle of $95^{\circ} \mathrm{C}$ for $10 \mathrm{~min}$; followed by 45 cycles of $95^{\circ} \mathrm{C}$ for $10 \mathrm{sec}, 60^{\circ} \mathrm{C}$ for $10 \mathrm{sec}, 72^{\circ} \mathrm{C}$ for $8 \mathrm{sec}$; and a final cycle of cooling at $40^{\circ} \mathrm{C}$ for 30 sec. The melting curve analysis was validated between temperatures of $65^{\circ} \mathrm{C}$ to $95^{\circ} \mathrm{C}\left(0.05^{\circ} \mathrm{C} / \mathrm{s}\right)$. The expression level of the UBIQUITIN reference gene transcript was determined in both the treated and untreated seedlings. The comparative threshold cycle $\left(C_{t}\right)$ method was used to quantify relative changes in the target gene expression in comparison to that of the UBIQUITIN reference gene (Jain et al., 2006). Ratios of the target gene expression to that of the reference gene in the untreated (control) and treated seedlings were calculated using the comparative $\mathrm{C}_{\mathrm{t}}$ method $\left(\Delta \Delta \mathrm{C}_{\mathrm{t}}\right)$ with an efficiency correction (Pfaffl, 2001; Willems et al., 2008). The calibration standard curve was established using the $\mathrm{C}_{\mathrm{t}}$ method and the log of cDNA in 5x serial dilutions before the results was analyzed with the LightCycler 4.0 software.

\section{Results and discussion}

\subsection{Genes expressed during drought and salt stresses}

The sequences of discrete fragments amplified via DDRT-PCR were compared against annotated sequences deposited in the MSU Rice Genome Annotation Project database (http://rice. plantbiology.msu.edu/index.shtml). The sequence of one amplified fragment from the drought-stress treated seedlings and the sequence of another amplified fragment from the salt-stress treated seedlings showed a $100 \%$ identity at the nucleotide level to a putative rice gene encoding the apocytochrome $f$ precursor (LOC_Os01g65902). Similarly, a perfect match at the nucleotide level was also found between an amplified fragment originating from seedlings that had undergone saltstress and a putative rice gene coding for the ATP synthase B chain (LOC_Os10g38272). Both the apocytochrome $f$ precursor and the ATP synthase B chain are important components of the protein complexes of the electron transport chain. The electron transport chain is known to be involved in abiotic stress responses via the production of reactive oxygen species (Mittler et al., 2004; Jaspers and Kangasjarvi, 2010). Therefore, it is not surprising that the activity of genes coding for proteins that form part of the complexes of the electron transport chain was detected in rice seedlings exposed to salt and drought stresses.

\subsection{Drought stress effect on the apocytochrome f precursor}

The gene coding for the apocytochrome $f$ precursor in rice seedlings underwent a drastic reduction in its expression level as an immediate response to drought stress. The ten-fold decrease in expression of the gene relative to that of the untreated seedlings occurred after only one day of exposure to drought stress (Fig. 1a). However, the expression of the gene recovered back up to levels comparable to that of the untreated seedlings when the drought-stress treatment continued for two days or more. In addition to responding to drought stress, the activity of the apocytochrome $f$ precursor was also detected in rice seedlings subjected to salt stress. However, the expression of the gene was not significantly different from that of the untreated seedlings regardless of the duration of salt-stress treatment (Fig. 1b). Taken together, it shows that the gene encoding the apocytochrome $f$ precursor is more responsive to drought stress than salt stress. a

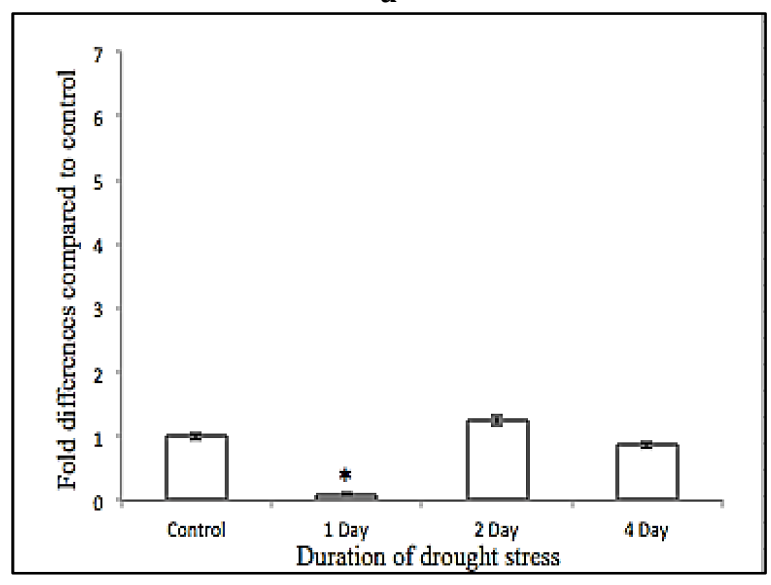

b

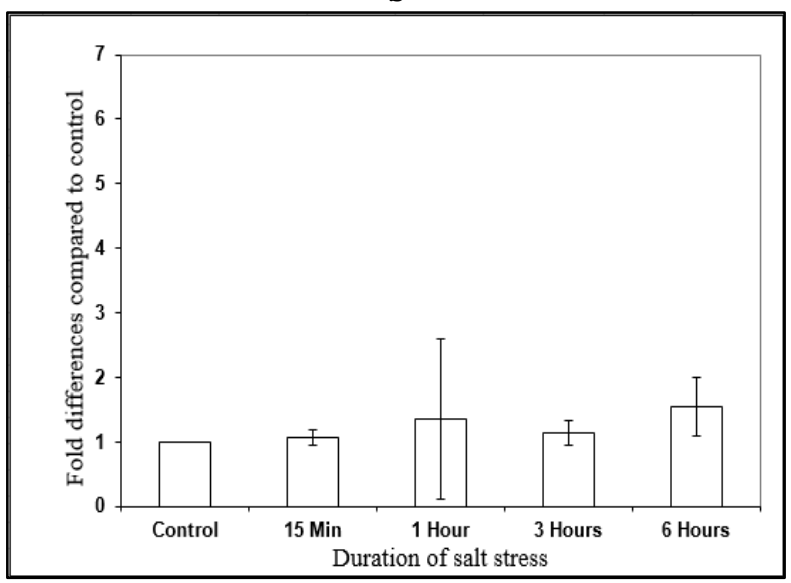

Fig. 1: Relative expression levels of the apocytochrome $f$ precursor in rice seedlings under drought and salt stress (Rice seedlings, 14 days after seed sowing, were subjected to either (a) drought-stress treatment for a duration of 1,2 or 4 days, or (b) salt-stress treatment for a duration of $15 \mathrm{~min}, 1$ hour, 3 hours or 6 hours. Comparisons of the relative expression levels of the apocytochrome $f$ precursor in treated seedlings to that of the control (untreated seedlings) were done using the Student's

$t$-test. An asterisk signifies a statistically significant difference compared to the control (untreated seedlings) at $\mathrm{P}<0.05$.) 


\subsection{Salt stress effect on the ATP synthase B chain}

The expression of the gene encoding the ATP synthase B chain was up-regulated by 2 -fold relative to that of the untreated seedlings when rice seedlings were exposed to salt stress for 1 hour (Fig. 2 ). There seemed to be a 3 -fold increase in the relative expression level of the gene after $15 \mathrm{~min}$ of treatment but the large standard deviation rendered the increase statistically insignificant. The relative expression levels of the gene went down to levels similar to that of the untreated seedlings when the duration of treatment was extended for 3 hours or more. This suggests that an exposure to salt stress seems to instantly boost the expression level of the gene coding for the ATP synthase B chain but the effect is short-lived and peters out after 1 hour.

\subsection{Structure of cytochrome $b_{6} f$ complex and ATP synthase}

The cytochrome $b_{6} f$ complex is involved photosynthetic electron transport chain. The cytochrome $b_{6} f$ complex functions as a dimer with a total molecular mass of $\sim 220 \mathrm{kDa}$, and each monomer consists of eight different subunits (Cramer et al., 2006; Baniulis et al., 2009). ATP synthase is exclusively localized in the unstacked parts of the thylakoid membrane, the stroma lamellae and end membranes (Miller and Staehelin, 1976). It utilizes the proton motive force (pmf) across the thylakoid membrane to drive ATP synthesis. In darkness, ATP synthase is inactivated, to prevent ATP hydrolysis when the pmf across the thylakoid membrane is low. No precise structure of the entire complex has been established to date. ATP synthase activity in higher plants is strictly regulated.

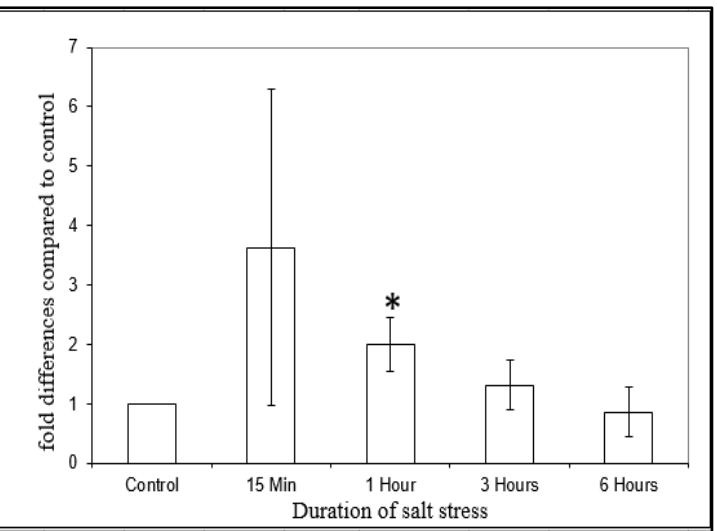

Fig. 2: Relative expression levels of the ATP synthase B chain in rice seedlings under salt stress (Rice seedlings, 14 days after seed sowing, were subjected to salt-stress treatment for a duration of $15 \mathrm{~min}, 1$ hour, 3 hours or 6 hours. Comparisons of the relative expression levels of the ATP synthase B chain in treated seedlings to that of the

control (untreated seedlings) were done using the

Student's $t$-test. An asterisk signifies a statistically significant difference compared to the control (untreated seedlings) at $\mathrm{P}<0.05$ )

\subsection{Cytochrome $b_{6} f$ and ATP synthase involved in metabolic pathway}

Changes in cytochrome $f$ and ATPase synthase can affect both photosynthetic electron transport rates and Calvin-Benson cycle activity. Fluctuations occurring on the time scale of seconds to hours mostly trigger rapidly reversible changes in photosynthetic light utilization and electron partitioning between $\mathrm{NADP}^{+}$reduction and alternative pathways. The Photosynthesis pathway of cytochrome $\mathrm{f}$ and ATPase synthase is shown in Fig. 3.

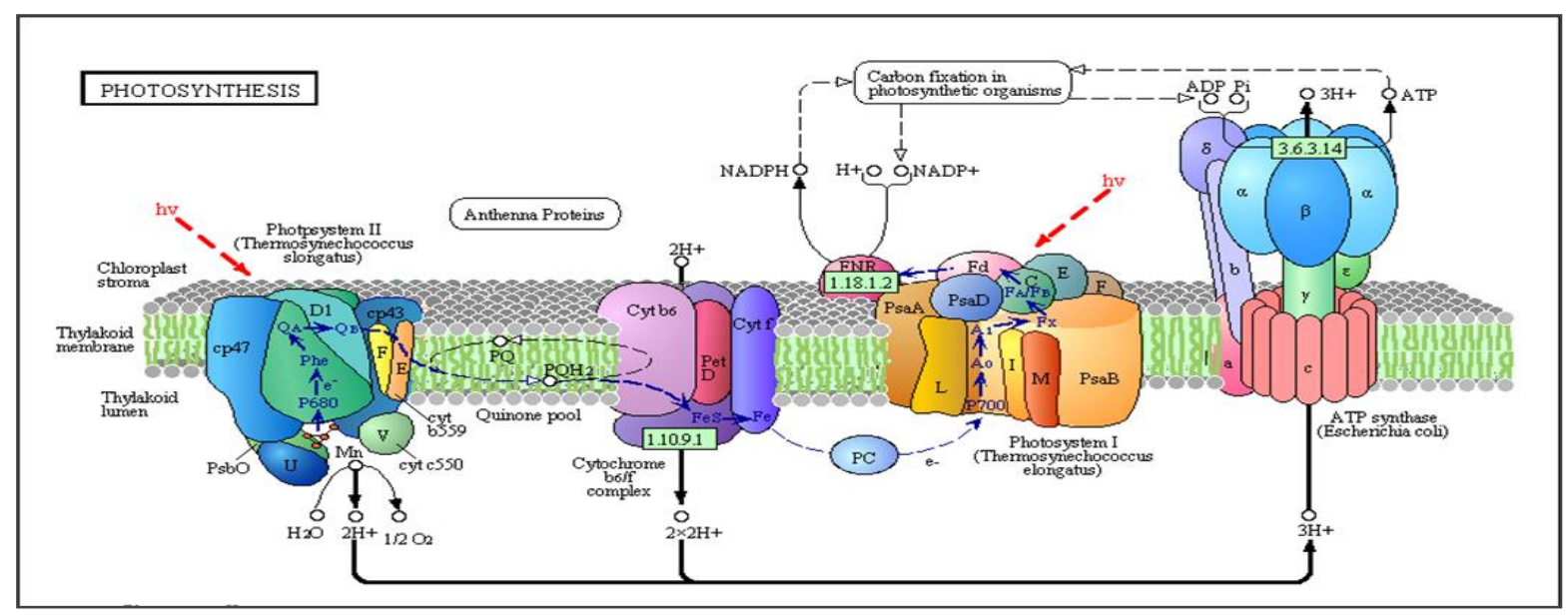

Fig. 3: Cytochrome fand ATP synthase involved in electron transport chain of photosynthesis pathways

Cytochrome $\mathrm{f}$ is the largest subunit of cytochrome $b_{6} f$ complex. The linear electron transport that passes through the cytochrome (Cyt) $b_{6} f$ complex generates a proton gradient across the thylakoid membrane (D pH); (Allen, 2003). Together with the proton gradient generated by the water-splitting complex associated with PSII, enable ATP production by the ATP synthase complex (Müller et al., 2001). There is also a cyclic electron transport that depends on the PSI (CEF-PSI), photochemical reactions and also passes through the Cyt $b_{6} f$ complex. The cyclic electron transport can generate a $\Delta \mathrm{pH}$ and drives ATP synthesis by ATP synthase without concomitant generation of NADPH (Shikanai, 2007). NADPH and 
ATP generated by light reactions are then utilized in the Calvin-Benson cycle and other assimilatory reactions.

These results reveal that Cytochrome $f$ and the ATP synthase are involved in the drought and salt stress response. The further study will help us to discover how the Cytochrome $\mathrm{f}$ and ATP synthase activity is regulated and to understand the function in response to environmental stresses.

\section{Conclusion}

Abiotic stresses appear to affect the expression of genes coding for proteins that are involved in the electron transport chain. The effects of abiotic stresses on gene expression are short-lived and drastic. The change in the expression level of the gene encoding the apocytochrome $f$ precursor occurred within one day of exposure to drought stress whereas that of the gene encoding the ATP synthase B chain tool place within an hour of being exposed to salt stress. Further studies are required to establish the usefulness of the two genes as molecular markers for breeding or engineering drought and salt tolerant rice varieties.

\section{Acknowledgement}

Grand from the Department of social welfare, Maharashtra state government, India, supported this study. The MR253 variety of rice seeds was donated by MARDI.

\section{References}

Allen JF (2003). Cyclic, pseudocyclic and noncyclic photophosphorylation: new links in the chain. Trends in Plant Science, 8(1): 15-19.

Baniulis D, Yamashita E, Whitelegge JP, Zatsman AI, Hendrich MP, Hasan SS, and Cramer WA (2009). Structure-function, stability, and chemical modification of the cyanobacterial cytochrome b6f complex from Nostoc sp. PCC 7120. Journal of Biological Chemistry, 284(15): 9861-9869.

Boudsocq M and Laurière C (2005). Osmotic signaling in plants. Multiple pathways mediated by emerging kinase families. Plant Physiology, 138(3): 1185-1194.

Cramer WA, Zhang H, Yan J, Kurisu G, and Smith JL (2006). Transmembrane traffic in the cytochrome b $6 \mathrm{f}$ complex. Annual Review of Biochemistry, 75: 769-790.

FAO (2009). High level expert forum - how to feed the world in 2050. Economic and social development department. Food and Agricultural Organization of the United Nations, Rome, Italy.

Finkelstein RR, Gampala SS, and Rock CD (2002). Abscisic acid signaling in seeds and seedlings. The Plant Cell, 14(suppl 1): S15-S45.
Fujita Y, Fujita M, Shinozaki K, and Yamaguchi-Shinozaki K (2011). ABA-mediated transcriptional regulation in response to osmotic stress in plants. Journal of Plant Research, 124(4): 509-525.

Hakim MA, Juraimi AS, Begum M, Hanafi MM, Ismail MR, and Selamat A (2010). Effect of salt stress on germination and early seedling growth of rice (Oryza sativa L.). African Journal of Biotechnology, 9(13): 1911-1918.

Jain M, Nijhawan A, Tyagi AK, and Khurana JP (2006). Validation of housekeeping genes as internal control for studying gene expression in rice by quantitative real-time PCR. Biochemical and Biophysical Research Communications, 345(2): 646-651.

Jaspers P and Kangasjärvi J (2010). Reactive oxygen species in abiotic stress signaling. Physiologia Plantarum, 138(4): 405413.

Lee DG, Woong Park K, Young An J, Geol Sohn Y, Ki Ha J, Yoon Kim $\mathrm{H}$, and Young Kang K (2011). Proteomics analysis of saltinduced leaf proteins in two rice germplasms with different salt sensitivity. Canadian Journal of Plant Science, 91(2): 337 349.

Liang P and Pardee AB (1992). Differential display of eukaryotic messenger RNA by means of the polymerase chain reaction. Science, 257(5072): 967-971.

Miller KR and Staehelin LA (1976). Analysis of the thylakoid outer surface. Coupling factor is limited to unstacked membrane regions. Journal of Cell Biology, 68(1): 30-47.

Mittler R, Vanderauwera S, Gollery M, and Van Breusegem F (2004). Reactive oxygen gene network of plants. Trends in Plant Science, 9(10): 490-498.

Müller P, Li XP, and Niyogi KK (2001). Non-photochemical quenching. A response to excess light energy. Plant Physiology, 125(4): 1558-1566.

Pfaffl MW (2001). A new mathematical model for relative quantification in real-time RT-PCR. Nucleic Acids Research, 29(9): e45. https://doi.org/10.1093/nar/29.9.e45

Rodríguez M, Canales E, Borroto CJ, Carmona E, Lopez J, Pujol M, and Borrás-Hidalgo $O$ (2006). Identification of genes induced upon water-deficit stress in a drought-tolerant rice cultivar. Journal of Plant Physiology, 163(5): 577-584.

Shanker AK and Venkateswarlu B (2011). Abiotic stress in plants mechanisms and adaptations. InTech Publisher, Rijeka, Croatia: 428.

Shikanai T (2007). Cyclic electron transport around photosystem I: genetic approaches. Annual Review of Plant Biology, 58: 199-217.

Varshikar D and Ching TF (2015). Molecular Characterization of Rice (Oryza Sativa) Seedlings under UV, drought and salt Stress. Advances in Environmental Biology, 9(15): 50-55.

Willems E, Leyns L, and Vandesompele J (2008). Standardization of real-time PCR gene expression data from independent biological replicates. Analytical Biochemistry, 379(1): 127129.

XU J, Wei X, Li X, Chen L, Feng D and Zhu Z (2002). Isolation of rice EPSP synthase cDNA and its sequence analysis and copy number determination. Acta Botanica Sinica, 44(2): 188-192

Yamaguchi-Shinozaki K and Shinozaki K (2006). Transcriptional regulatory networks in cellular responses and tolerance to dehydration and cold stresses. Annual Review of Plant Biology, 57: 781-803. 